\title{
NUEVAS INTERVENCIONES EN EL TEATRO ROMANO DE ITÁLICA: ALGUNAS APRECIACIONES SOBRE SU EVOLUCIÓN CONSTRUCTIVA Y SU SISTEMA DE ACCESO
}

\section{NEW INTERVENTIONS IN THE ROMAN THEATRE OF ITALICA: SOME COMMENTS ON ITS CONSTRUCTIVE EVOLUTION AND SYSTEM OF ACCESS}

\author{
por \\ OLIVA RODRÍGUEZ GUTIÉRREZ y \\ MANUEL VERA REINA
}

RESUMEN En este trabajo se presentan brevemente los resultados obtenidos en las últimas intervenciones arqueológicas llevadas a cabo en el teatro romano de Itálica (1999). Éstas, motivadas por trabajos de saneamiento, han tenido como escenario sus accesos a la orchestra: los itinera. En ellos se ha podido comprobar una dinámica y a la vez compleja evolución constructiva paralela a la que ya ha sido apuntada por las recientes investigaciones llevadas a cabo en otras áreas del edificio o el análisis estilístico de sus elementos arquitectónicos. Algunos de los datos más novedosos proceden del extremo meridional del iter sur, donde la construcción de una potente estructura en opus caementicium, ajena al teatro, obligó, a pesar de ello, a llevar a cabo importantes reformas en algunos sectores del edificio.

\begin{abstract}
In the following paper we present the results obtained from the last archaeological excavations carried out on the Roman Theatre of Italica (1999). The intervention has been made at the itinera, the lateral entrances to the orchestra, despite of their necessary drainage. We have obtained new interesting information about the building development which joins in this way to the known facts got through the recent research on the theatre and the analysis of its architectural items. The most novel information comes from the south edge of the aditus maximus, where the building of a huge opus caementicium structure, out of the theatre, forced to make important reforms in some areas of the building.
\end{abstract}

\section{Introducción:}

Es de sobra conocida la historia reciente del teatro romano de Itálica (Rodríguez Gutiérrez 1997; Rodríguez Gutiérrez 1998: 71 ss.; Caballos et alii 1999: 88). Si bien se tenía noticia de su existencia ya desde el siglo XVIII, las primeras excavaciones no se iniciaron hasta mucho después, a comienzos de la década de los setenta del presente siglo (Luzón 1982). A partir de entonces, las intervenciones en su solar 
se sucedieron con mayor o menor continuidad, simultaneándose incluso, desde fines de los ochenta, con un ambicioso proyecto de restauración estructurado en diversas fases (Jiménez 1982; 1989), cuya segunda etapa fue propiciada por la celebración de la Exposición Universal celebrada en Sevilla en 1992 (Jiménez et alii 1991-92).

En 1995, la entidad de los hallazgos en el límite noreste del recinto actual del teatro (Romo 1995) obligó a plantear la modificación del proyecto inicial del concebido como edificio de recepción y servicios (Montero 1993), interrumpiéndose entonces los trabajos tanto arqueológicos como de restauración arquitectónica.

No obstante, los años han pasado, y lo que no ha cesado ha sido el deterioro del teatro durante los mismos. Si bien cabe señalar el crecimiento incontrolado de vegetación y el vertido y/o acumulación de basuras en su solar, especialmente nocivos han sido los efectos de las lluvias torrenciales de los años 96 y 97 . Éstos han motivado la puesta en marcha de una serie de obras preventivas de saneamiento, a la espera de la reanudación de los trabajos de restauración dentro de un proyecto de mayor alcance.

La intervención que aquí abordamos corresponde al exhaustivo seguimiento arqueológico que ha acompañado a las citadas labores de conservación preventiva, llevada a cabo durante los meses de enero y febrero de 1999. En líneas generales, la actividad ha consistido en una limpieza de las diversas áreas de intervención (fig. 1) que, en aquellos lugares donde los sedimentos eran de la potencia suficiente, se ha realizado por medio del empleo de un escrupuloso método estratigráfico (Lám. I).

En primer lugar se ha llevado a cabo una revisión de los resultados obtenidos hasta el momento en las diversas intervenciones y estudios realizados en y sobre el edificio. El estado de la cuestión de la evolución constructiva del mismo puede ser resumido, a grandes rasgos, como sigue. Su construcción, entendiendo como tal el proyecto de planificación y el levantamiento de los principales elementos que caracterizan a un edificio teatral romano, se llevó a cabo en torno al cambio de Era. Los materiales presentes en los rellenos de las cimentaciones de la cauea señalan los años inmediatamente anteriores a este momento (Corzo 1993: 161), mientras que la dedicación por parte de una serie de municipes (CILA 382 y 383) de diversos elementos estructurales del edificio (scaenae, itinera, proscaenium, orchestra, porticus) sugiere una cronología tardoaugusteo/tiberiana para la culminación de este proyecto constructivo inicial. No obstante, el hallazgo en el transcurso de las primeras excavaciones de una serie de fustes estriados de columna, en caliza y estucados en azul, hizo proponer la posible existencia de una escena primitiva previa a la posterior marmórea (Luzón 1982: 186), si bien sus módulos no parecen ajustarse a los requerimientos de la estructura (Jiménez 1982: 290). En posteriores excavaciones, a fines de los años ochenta, R. Corzo creyó identificar, en el postscaenium, las trazas de esta primera escena. Lo hizo a través de la impronta de una serie de columnas que, en origen, habrían sido las encargadas de sustentar la galería oeste de la porticus post scaenam, adosada a una escena de muro más estrecho, previa a la construida posteriormente en la que se basa la restitución actual (Corzo 1990: 46-47; Rodríguez Gutiérrez 2000: fig. 15). Del mismo modo, este autor señala una fase flavia en la que la escena se habría visto transformada, uniéndose a la cavea por medio del alzado de los muros de las uersurae, momento en el que un edificio de cavea y escena independientes habría adoptado, definitivamente, una apariencia romana (Corzo 1990: 76; 1993: 166).

En la intervención que aquí presentamos se pretendían identificar las fases anteriores en el iter sur, a fin de aportar nuevos datos que se unieran a los ya existentes y a aquéllos que, en algunos sectores, se mantienen tan sólo como hipotéticos y cuya realidad resulta hoy difícil constatar, dada la generalizada incorporación de fábricas modernas en el curso de los trabajos de restauración. 


\section{Naturaleza de los trabajos:}

Desde que el teatro comenzara a ser excavado, a comienzos de la década de los setenta, se han sucedido en su solar campañas de excavación arqueológica y trabajos de restauración. A pesar de ello, aún son muchas las áreas que precisan de intervenciones, al menos de conservación preventiva que, a la espera de un programa más amplio, paralicen el deterioro de esos sectores y garanticen la seguridad en el recinto del teatro.

La intervención, en el sector más meridional del iter sur, era especialmente compleja dada la pronunciada diferencia de cota existente entre los niveles de uso del antiguo teatro y los actuales de las viviendas del pueblo de Santiponce que aún se encuentran en su perímetro (Lám. I). Las torrenciales lluvias invernales de los últimos años han producido que los superiores, más modernos, se hayan desplomado paulatinamente sobre los inferiores, poniendo en peligro, no solamente la estabilidad en el área, sino también la integridad de los niveles más antiguos. A todo ello debe además unirse una acusada lacra estética.

Se hacía necesaria una limpieza en extensión del área, así como la definición del comportamiento de las estructuras murarias, a fin de poder consolidarlas y reintegrarlas en una altura suficiente y adecuada con su realidad antigua, de manera que ellas mismas pudieran servir en adelante como contrafuertes y contenedores de las tierras superiores.

La intervención arqueológica acompañó, por tanto, a una serie de labores de saneamiento encargadas de subsanar en lo posible los daños causados por las repetidas inundaciones del edificio: la instalación de una nueva bomba de evacuación de las aguas que emanan de forma natural en el solar del teatro; la restauración -por tercera vez tras su exhumación a comienzos de los setenta-de las pinturas de decoración del murus pulpiti (Amores y Rodríguez Hidalgo 1986: 76-77); y la limpieza del hyposcaenium, hoy espacio subterráneo practicable con cubierta de hormigón.

Estas labores han propiciado, sin duda, la actuación en algunas áreas fundamentales para la comprensión del desarrollo constructivo del edificio:

a) el sector meridional del iter sur, allí donde se produce su conexión con el conocido como muro de San Antonio (Corzo 1993: 163; Roldán 1993: 226-227) (unidades de intervención 1 y 3) (fig.1b), con el fin de determinar las posibles reformas que sobre su sistema de accesos habría provocado la construcción de esta potente estructura de opus caementicium.

b) uno de los alvéolos de cimentación de la summa cauea que limitaban con el muro oeste del iter sur (unidad de intervención 2) (fig. 1b).

c) el iter norte, en cuyo extremo septentrional se llevó a cabo un pequeño sondeo (unidad de intervención 4), además de limpiarse su cloaca central (unidad de intervención 5) (fig. 1c).

Se planteaba así la posibilidad de dar respuesta a cuestiones arqueológicas no solucionadas hasta el momento en intervenciones anteriores e, incluso, constatar algunas de las afirmaciones por ellas planteadas.

No obstante, el análisis previo de los planos de localización de las áreas excavadas a lo largo de la historia de los trabajos en el teatro (Rodríguez Gutiérrez 1998: figs. 17-24), puso sobre aviso de la alteración, en el curso de campañas previas, de las áreas objeto de nuestra intervención. De esta forma, sus resultados se han visto desafortunadamente condicionados por las excavaciones anteriores que, en el caso del iter sur, permanecen inéditas y sus materiales en el almacén del teatro a la espera de ser estudiados. 


\section{La intervención arqueológica y la interpretación de los hallazgos:}

Como ya ha sido indicado anteriormente, los trabajos arqueológicos se han realizado en dos áreas principales: iter norte e iter sur. En cada uno de ellos se han distinguido varias unidades de intervención (en adelante U.I.):

Las UU.II.1 y 3 (fig. 1b) se sitúan en el extremo más meridional del aditus, con una superficie total de 29 metros cuadrados. Al comienzo de las labores de 1999 se hallaban parcialmente colmatadas por los niveles hasta allí arrastrados por las lluvias. En su sector este aflora una masa de opus caementicium correspondiente a una bóveda caída que, parcialmente, se introduce bajo lo que hoy es la calle Eduardo Ibarra, quedando, por tanto, fuera del recinto del teatro y del alcance de nuestra actuación (lám II). Metodológicamente se creyó oportuna la diferenciación entre ambas ya que, en un principio, existía un acusado desnivel así como apenas un estrecho pasillo de comunicación entre ellas. La U.I.2 corresponde a uno de los alvéolos cuadrangulares más orientales de la cimentación de la summa cavea, apoyándose sobre el muro oeste del iter (lám. III).

A su vez, en el iter norte (fig. 1c), se llevó a cabo un pequeño sondeo en su extremo septentrional, U.I.4, de apenas dos metros cuadrados de superficie, junto al muro oeste del mismo. Tuvo por objeto identificar la fosa de cimentación del citado muro, por lo que se eligió para ello el lugar que, a priori, se consideró menos afectado por los trabajos de excavación y restauración de 1990-91. La estratigrafía se vio interrumpida a 1,52 metros de profundidad por la aparición del nivel freático. La U.I.5, objeto de una exhaustiva limpieza, coincide con la cloaca que circulaba bajo este iter (lám. IV); fue excavada a fines de los ochenta, momento del que poseemos valiosa información documental sobre ella (Corzo y Toscano 1990).

En el iter sur, la alteración e incluso vaciado del sector llevada a cabo en la campaña de excavaciones de 1991, de las que, como ya hemos señalado, carecemos de documentación, llevó a plantear una intervención de escrupulosa metodología, con objeto de localizar y aislar los posibles escasos niveles que aún pudieran permanecer inalterados. Con ellos y el análisis constructivo de las estructuras, se ha procurado trazar una lectura diacrónica coherente de este área del edificio, obteniendo interesantes resultados.

\subsection{En torno a la cauea:}

Tras una primera preparación del terreno, en la que se recortó parte de la colina y se realizó en opus africanum (que no mixtum, según Roldán 1993, 223, fig. 35) un potente muro quebrado de contención de las tierras superiores (Corzo 1993: 160), se procedió a la construcción de la cauea, con una cimentación de estructura alveolar. En el curso de nuestra intervención se ha documentado cómo el graderío, al menos por el este, se apoyó en un potente muro de sillares a soga y tizón (de módulo 115 x 53 x $52 \mathrm{~cm}$; fig. 2), a su vez, uno de los alzados encargados de configurar el aditus maximus.

La excavación del alvéolo de cimentación de la cauea (U.I.2; lám. III) ha permitido confirmar el procedimiento seguido para su construcción, ya identificado en otros puntos de su estructura en el curso de excavaciones precedentes y que aquí sintetizamos:

1) Realización de una serie de zanjas anulares allí donde se levantarían los muros concéntricos de la cavea.

2) En algunos puntos también se llevan a cabo zanjas para las riostras, los muros radiales que funcionan a modo de tirantes entre los anteriores.

3) Se construyen las cimentaciones de estos muros, cimientos a su vez de la cauea, vertiendo piedras de tamaños y formas irregulares a hueso en las zanjas anteriores. 
4) Se comienzan a elevar los muros de opus caementicium valiéndose de encofrados de madera. Las tongadas son de aproximadamente $60 / 70 \mathrm{~cm}$ de altura. Los caementa son de tamaño considerable $(20-25 \mathrm{~cm})$ y el mortero abundante en cal. Las fábricas en ocasiones se completan con sillares de caliza fosilífera en puntos que no siguen aparentemente regularidad y ritmo alguno. En el caso de la celdilla por nosotros excavada, el muro radial más occidental se realizó con posterioridad a la riostra oriental, que traba con los anulares y que fue construida a la vez que éstos.

5) Los rellenos interiores se vierten en dos fases intercaladas en la propia construcción de los muros tal y como lo demuestran los niveles de aplanamiento y regularización. Éstos son abundantes en fragmentos de caliza fosilífera y esquirlas de piedra caliza producto de la obtención de los caementa a pie de obra.

6) En este sector de la cavea no se han conservado los niveles superiores de la misma, tan sólo los correspondientes a su cimentación. No obstante, tal y como se ha observado en el curso de campañas anteriores, los alvéolos estuvieron cubiertos por una cama de escasa potencia realizada con tierra y piedras sobre la que directamente apoyaron los sillares que configuraban las gradas.

\subsection{En torno a la evolución constructiva de los itinera:}

Del mismo modo, la intervención en el extremo meridional del iter sur (Fig. 3), ha permitido documentar algunas de las fases que ya fueron reconocidas durante las excavaciones en el iter norte (Corzo 1993: 165). No obstante, en el primero de ellos se ha observado además cómo, a comienzos del siglo II d.C., agentes externos al teatro obligaron a reformar puntualmente el área, como a continuación veremos.

Fase I (fig. 4). De forma coetánea al graderío se construyen los itinera de acceso a la orchestra (ambos elementos se encuentran entre los dedicados por los Pollio en la inscripción monumental ante el proscaenium, CILA 383). Sus muros, en un principio y muy probablemente, configuraban un acceso longitudinal. Eran de paramento de sillares de piedra caliza fosilífera, dispuestos a soga y tizón, de módulo 115 x 53 x 52 $\mathrm{cm}$ (fig. 2, fase I). A pesar de su precario estado de conservación y de la reintegración de la que ha sido objeto en el curso de la restauración, todavía puede apreciarse, en el núcleo de opus caementicium del muro oeste del iter sur, el arranque de su bóveda de cubierta. Los materiales exhumados en la fosa de cimentación del muro oeste del iter norte -el pequeño sondeo U.I.4- parecen conducir también a estas fechas de en torno al cambio de Era, comienzos del siglo I d.C.

Fase II (fig. 4). En un segundo momento, datado por R. Corzo en época flavia (Corzo 1993: 165) y del que en el curso de la intervención de 1999 no se han obtenido materiales susceptibles de aportar cronologías fidedignas, estos accesos fueron reformados, pasando a ofrecer una circulación en codo, es decir, formando noventa grados en dirección a los parascaenia cuyos muros de las uersurae, según R. Corzo, datarían también de este momento. Para esta reforma de los itinera se empleó una fábrica semejante a la inicial (fig. 2, fase II), si bien la perdida de la horizontalidad de las hiladas, la calidad de la piedra, mucho más sensible a la meteorización, y lo que es más importante, el módulo del paramento (ahora 90 x 53 × 28 $\mathrm{cm}$ ) no deja ninguna duda al respecto (lám. V). Especialmente en un área en la que la alteración de las estratigrafías originales impide obtener datos cronológicos fiables de los materiales arqueológicos exhumados, ha sido especialmente valiosa la aplicación del método estratigráfico para el análisis constructivo de las estructuras murarias.

Este cierre del aditus en su límite sur, al igual que ya se documentó en el norte de forma más acusada, implicó la reforma de las extremidades de la cauea. De esa forma, se observa cómo fueron añadidos al menos dos nuevos alvéolos de cimentación, cosa que, muy probablemente, se manifestara también en su parte superior, allí donde se producía la conexión entre el graderío y el muro de la versura. La evidencia 
de esta segunda fase constructiva, en el caso del iter sur, se vio reducida por la posterior reforma sufrida por el área a comienzos del siglo II.

Fase III (fig. 4). Fue entonces cuando se construyó una estructura en opus caementicium, que sirvió de apoyo a una terraza que se extendió a partir de la summa cauea del teatro. En el estado actual de la investigación, dicha terraza se apunta como una probable área pública, reforma incluso de un espacio ya existente desde época republicana y que, en el sector que nos ocupa, se materializa en el conocido como muro de San Antonio. De ella procederían muchos de los materiales recuperados en el teatro, entre ellos, las célebres esculturas de Artemis, Hermes y Afrodita. Esta nueva obra, ajena al teatro pero en contacto directo con él, obligó a la transformación del extremo meridional del iter sur, donde se levantó una potente estructura de sillares encargada de soportar los empujes de la primera (lám. VI). No obstante, este macizado de sillares de roca alberiza respetó, a grandes rasgos, la circulación definida en la fase anterior, es decir, la comunicación con el parascaenium sur y es muy posible que con el exterior del edificio, o quizá, un vestíbulo de distribución.

$\mathrm{El}$ aspecto actual del área, debido al generalizado expolio sufrido por sus materiales constructivos, de gran calidad, dificulta la comprensión de su realidad arquitectónica antigua. No obstante, las huellas dejadas por los sillares eliminados han permitido reconstruir la altura mínima que pudo ofrecer esta masiva construcción, variable, acorde con su función estructural. De esta forma, en su contacto con el muro de San Antonio se elevaba en forma de una potente fábrica maciza, encargada de amortiguar los pesos y empujes de aquél y de la obra en la que se integraba. Los muros concéntricos de la cauea, en este sector, se cortaron con el fin de adaptarse a la nueva organización estructural del área. Fue entonces cuando, para evitar que las presiones de la red alveolar cargasen directamente sobre la nueva construcción de sillares en roca alberiza, se resolvió rellenar, por medio de una obra de sillares semejante, el espacio interno de la antigua celdilla, ahora vacía y desprotegida (lám. VII). Si esto ocurría a partir del muro del iter este-oeste construido en la fase II, ante él la plataforma no fue recrecida, constituyendo la superficie de apoyo de su pavimento. Una hilada de grandes sillares (en los que se han conservado las oquedades centrales destinadas al empleo de la castañuela para su transporte y elevación) se cubrió con una gruesa capa de signinum de alto contenido calcáreo, conservada tan sólo muy localmente. El espesor de dicho acabado, así como la cota del pavimento ha podido ser confirmada por el hallazgo in situ de una de las dos piezas del quicio de la puerta de comunicación del aditus con el parascaenium correspondiente (lám. VIII).

En un momento posterior al abandono del edificio como lugar de espectáculos y que puede datarse hacia mediados del siglo IV d.C., el sector analizado fue también empleado como lugar de ocupación residual. De este momento es un horno (lám. IX), de cuya cámara sólo se han conservado las tres hiladas inferiores. Fue construido con ladrillos, probablemente, a juzgar por su diverso módulo y coloración, procedentes del expolio de otras estructuras. Su amortización ha sido fechada en la primera mitad del siglo V. Esta frecuentación del antiguo teatro podría incluso ponerse en relación con la primera fase de expolio de sus materiales constructivos; ya entonces, si bien continuó en momentos posteriores, habrían sido arrancados los grandes y bien trabajados sillares de roca alberiza que configuraban la potente estructura encargada de soportar los empujes del muro de San Antonio.

De especial interés ha resultado el análisis de la estratigrafía intacta detectada bajo la ya citada bóveda caída (lám. II), niveles que han sido parcialmente excavados, ante la imposibilidad de acceder al resto: por un lado, por el peligro que supone para la estabilidad de la masa de caementicium, por otro, por quedar al exterior del límite de la excavación.

Se han confirmado así las etapas fundamentales ya identificadas en otras áreas y por medio de otros criterios (como por ejemplo el análisis de elementos arquitectónicos: Rodríguez Gutiérrez 1998: passim). En primer lugar y directamente sobre la plataforma de sillares se identifica su nivel de amortización, de 
fines del siglo IV d.C., principios del siglo V d.C. A continuación se documenta un paquete de expolio, atribuido también a época tardía. Sobre éste, una serie de niveles informan de la reanudación de estas actividades coincidiendo con la ocupación islámica. Posteriormente, cerámicas de tradición andalusí nos sitúan, muy probablemente, en el momento de construcción del Monasterio de San Isidoro del Campo, fundado en 1301 (Luzón 1999: 19-21). De hecho, la reutilización de materiales de la ciudad romana para su construcción ha sido un fenómeno constatado en repetidas ocasiones. Por último, se identifican unos potentes rellenos que pueden adscribirse al traslado del pueblo de Santiponce a su emplazamiento actual, con motivo de las graves inundaciones de comienzos del siglo XVI (Luzón 1999: 24-25), momento en el que es de esperar la ocupación generalizada del área que terminara por ocultar definitivamente las estructuras del teatro que por entonces todavía afloraban en superficie.

\section{Conclusiones.}

Desafortunadamente se han visto condicionadas por una excavación muy limitada en el espacio y, a su vez, afectada por la alteración de niveles causada por campañas anteriores. A pesar de ello, los resultados han sido muy satistactorios permitiendo, no solamente confirmar hechos ya conocidos, sino también proporcionar novedosos datos sobre la evolución constructiva del edificio.

En la unidad de intervención 2, es decir, uno de los alvéolos de cimentación de la summa cauea, los resultados de la estratigrafía realizada corroboran muchas de las afirmaciones presentadas por R. Corzo (Corzo y Toscano 1990: 27-34) en sus intervenciones de fines de la década de los ochenta. La estructura de la cimentación de la cauea consistió en toda una serie de celdas cuadrangulares formadas por muros concéntricos y radiales, constituyendo así una arquitectura alveolar. Ambos juegos de muros fueron coetáneos, a pesar de no trabar siempre unos con otros, ya que, en ocasiones, las riostras fueron adosadas a los concéntricos. En la totalidad de la superficie de esta unidad de intervención se documenta un relleno en el que se aprecian niveles de aplanamiento coincidiendo con las hiladas de construcción de los muros de opus caementicium, de igual modo que también se reconocen otros en los que abundan los elementos empleados en la fabricación de dichos muros, como capas de mortero y lascas de caliza. La cronología de este relleno puede situarse a fines del siglo I a.C., tal y como parecen indicarlo los materiales cerámicos en él recuperados, de nuevo en consonancia con los hallados en otros alvéolos excavados anteriormente (Corzo y Toscano 1989: 84).

Del mismo modo, se ha reconocido un comportamiento simétrico de los itinera en sus dos primeras fases constructivas, tal y como ha permitido demostrar la intervención en el iter sur, en consonancia con la información obtenida en el norte en el curso de las campañas de fines de la década de los ochenta. La circulación longitudinal inicial del aditus maximus fue sustituida por sendos giros en sus extremos en dirección a los parascaenia. Sin embargo, la evolución paralela de ambos itinera cambió cuando, a comienzos del siglo II, fue construida la potente estructura de opus caementicium encargada de crear una terraza artificial destinada a alojar un espacio público, posiblemente ya existente desde tiempo atrás, y que en el sector sur se manifiesta actualmente en forma del conocido como muro de San Antonio. Allí la presión ejercida por ella sobre las estructuras del teatro provocó importantes reformas en el sector más meridional del iter sur: se construyó un potente macizado de sillares encargado de amortiguar sus empujes.

A modo de síntesis, los trabajos realizados en el iter sur han permitido establecer las siguientes fases constructivas (fig. 4):

1.- Se construyen los itinera. A este momento corresponde el primer tramo del paramento identificado en los muros oeste, es decir, el lienzo comprendido entre la orchestra y el rehundimiento practicado en la fábrica de sillares generando a modo de una hornacina de escasa profundidad. Coincidiría con la primera 
construcción del teatro, los itinera dedicados con Lucius Traianus Pollio y Titius Pollio, por tanto, en época tardoaugustea-tiberiana.

2.- En un segundo momento, aún por precisar, pero es posible que coincidente con la reforma identificada por R. Corzo en época flavia (Corzo y Toscano 1990: 75-78; Corzo 1993: 166), se produce la reforma de los muros del aditus a partir del rebaje anterior. La circulación en ambos itinera gira formando un ángulo de $90^{\circ}$.

3.- Los parodoi dejan de evolucionar de forma simétrica. En el iter sur se produce la ruptura del muro anteriormente reformado como consecuencia de la construcción de la estructura de sillares, encargada de soportar las presiones del muro de San Antonio, construido a comienzos del siglo II d.C. Esta reforma afectará también a la comunicación entre el exterior, el parascaenium sur y el iter correspondiente.

4.- Una vez abandonado el teatro como edificio de espectáculos, diversas áreas son ocupadas de forma residual. En el extremo meridional del iter sur se construye un horno en época tardorromana.

5.- En un momento, incluso ya contemporáneo al anterior, la piedra del sector, destacando la roca alberiza de la estructura de sillares, es expoliada sistemáticamente.

6.- En el sector excavado se reconocen nuevas fases de expolio, no resistiéndonos a relacionarlas con importantes pulsiones históricas, como la fundación y construcción del vecino Monasterio de San Isidoro del Campo (comienzos del siglo XIV) o el traslado a su solar actual del pueblo de Santiponce, a comienzos del XVI.

\section{Bibliografía:}

AMORES CARREDANO, F. y RODRÍGUEZ HIDALGO, J.M. (1986): "Itálica: memoria de actividades, 1986", Anuario Arqueológico de Andalucía, I, Conjuntos Arqueológicos: 75-77.

CABALLOS RUFINO, A.; MARÍN FATUARTE, J. y RODRÍGUEZ HIDALGO, J.M. (1999): Itálica arqueológica. Sevilla.

CORZO SÁNCHEZ, R. (1993): "El teatro romano de Itálica", en Teatros romanos de Hispania, Cuadernos de Arquitectura romana: 157-171. Murcia.

CORZO SÁNCHEZ, R. y TOSCANO SAN GIL, M. (1989a): Itálica. Excavaciones en el teatro (1988-89). Sevilla.

CORZO SÁNCHEZ, R. y TOSCANO SAN GIL, M. (1989b): Itálica. Excavaciones en el teatro (1989). Memoria. Excavación del cuadrante norte del pórtico. Sevilla.

CORZO SÁNCHEZ, R. y TOSCANO SAN GIL, M. (1990): Itálica. Excavaciones en el teatro (1990). Sevilla.

JIMÉNEZ MARTÍN, A. (1982): "Teatro de Itálica. Primera campaña de obras", Itálica (Santiponce, Sevilla), E.A.E., 121: 277-290. Madrid.

JIMÉNEZ MARTÍN, A. (1989): "Las columnas del teatro de Itálica", Homenaje al profesor Antonio Blanco Freijeiro: 277-318. Madrid.

JIMÉNEZ, A.; MONTERO, F.J. y RODRÍGUEZ, P. (1991-1992): "El temblor de la falsificación", Periferia, 11: 36-53. Sevilla.

LUZÓN NOGUÉ, J. Mª (1982): "El teatro romano de Itálica", El teatro en la Hispania romana: 183-191. Badajoz.

LUZÓN NOGUÉ, J. Ma (1999): Sevilla La Vieja. Un paseo histórico por las ruinas de Itálica. Sevilla. MONTERO FERNÁNDEZ, F.J. (1993): "Continente para un contenido II: la restauración del teatro romano de Itálica", en Teatros romanos de Hispania, Cuadernos de Arquitectura romana: 173-181. Murcia. 
RODRÍGUEZ GUTIÉRREZ, O. (1997): "El teatro romano de Itálica: historia en imágenes”, Revista de Arqueologia, $\mathrm{n}^{\circ}$ 192: 40-45.

RODRÍGUEZ GUTIÉRREZ, O. (1998): Introducción al estudio del teatro romano de Itálica: análisis de los elementos de sus órdenes arquitectónicos, Memoria de Licenciatura. Madrid.

RODRÍGUEZ GUTIÉRREZ, O. (2000): "La scaenae frons del teatro romano de Itálica. Ensayo de anaparástasis a partir del análisis de sus elementos arquitectónicos", AEspA, 73: 143-167.

RODRÍGUEZ GUTIÉRREZ, O.; VERA REINA, M. y VERDUGO SANTOS, J. (1999): Memoria de intervención. Teatro romano de Itálica (Santiponce, Sevilla). Enero-febrero 1999. Sevilla.

ROMO SALAS, A. (1995): Informe de la excavación arqueológica en el entorno del teatro de Itálica (Santiponce, Sevilla). Sevilla. 


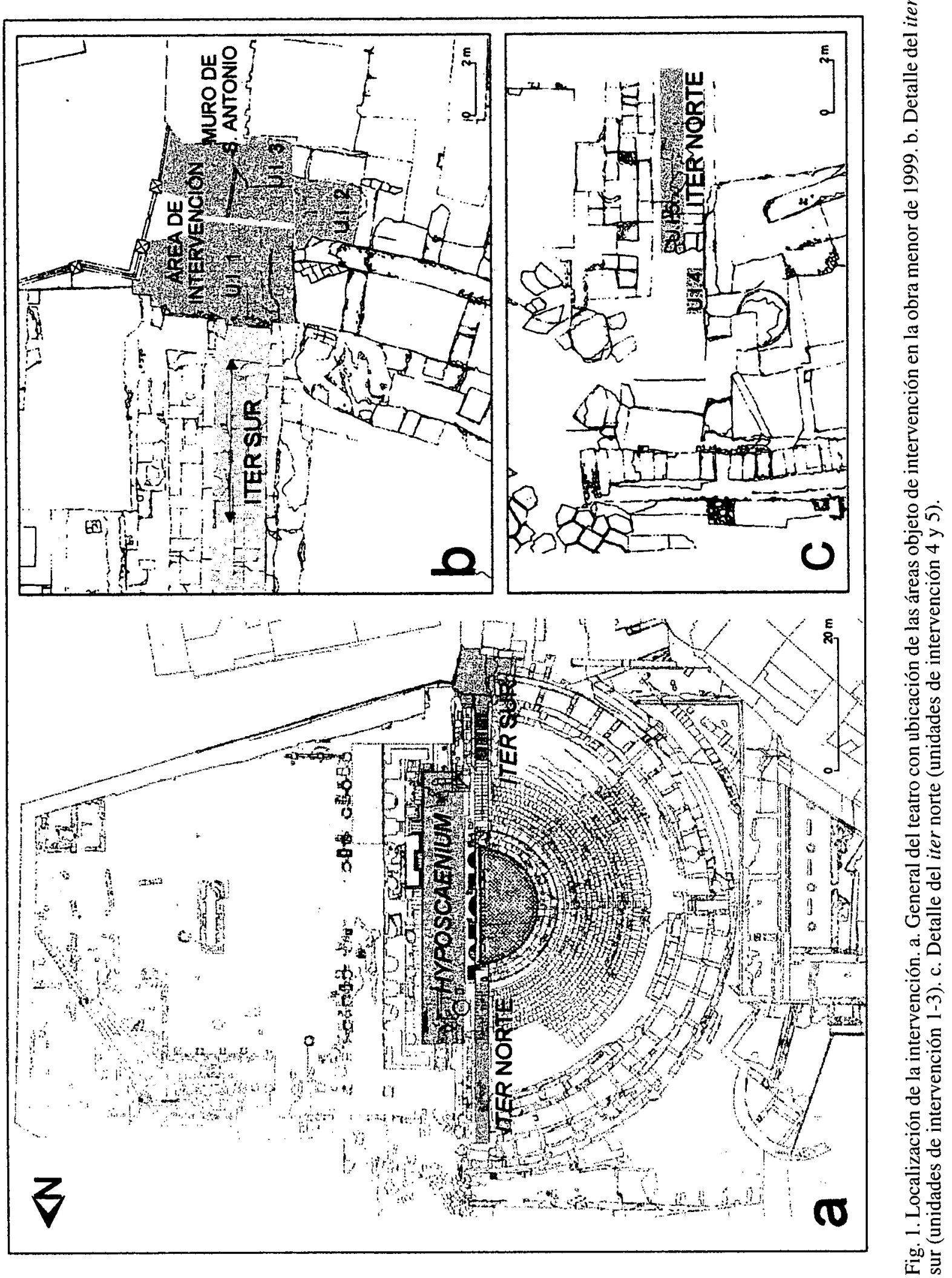




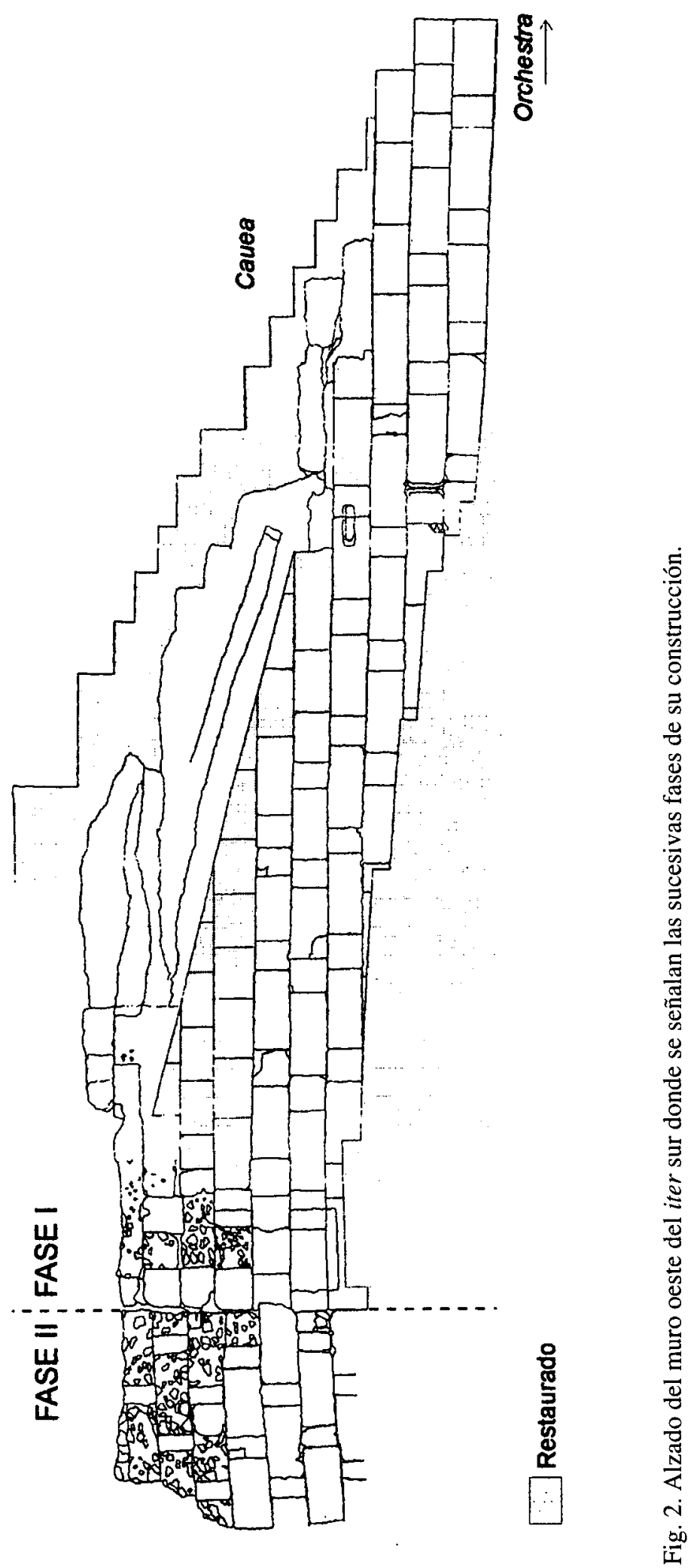




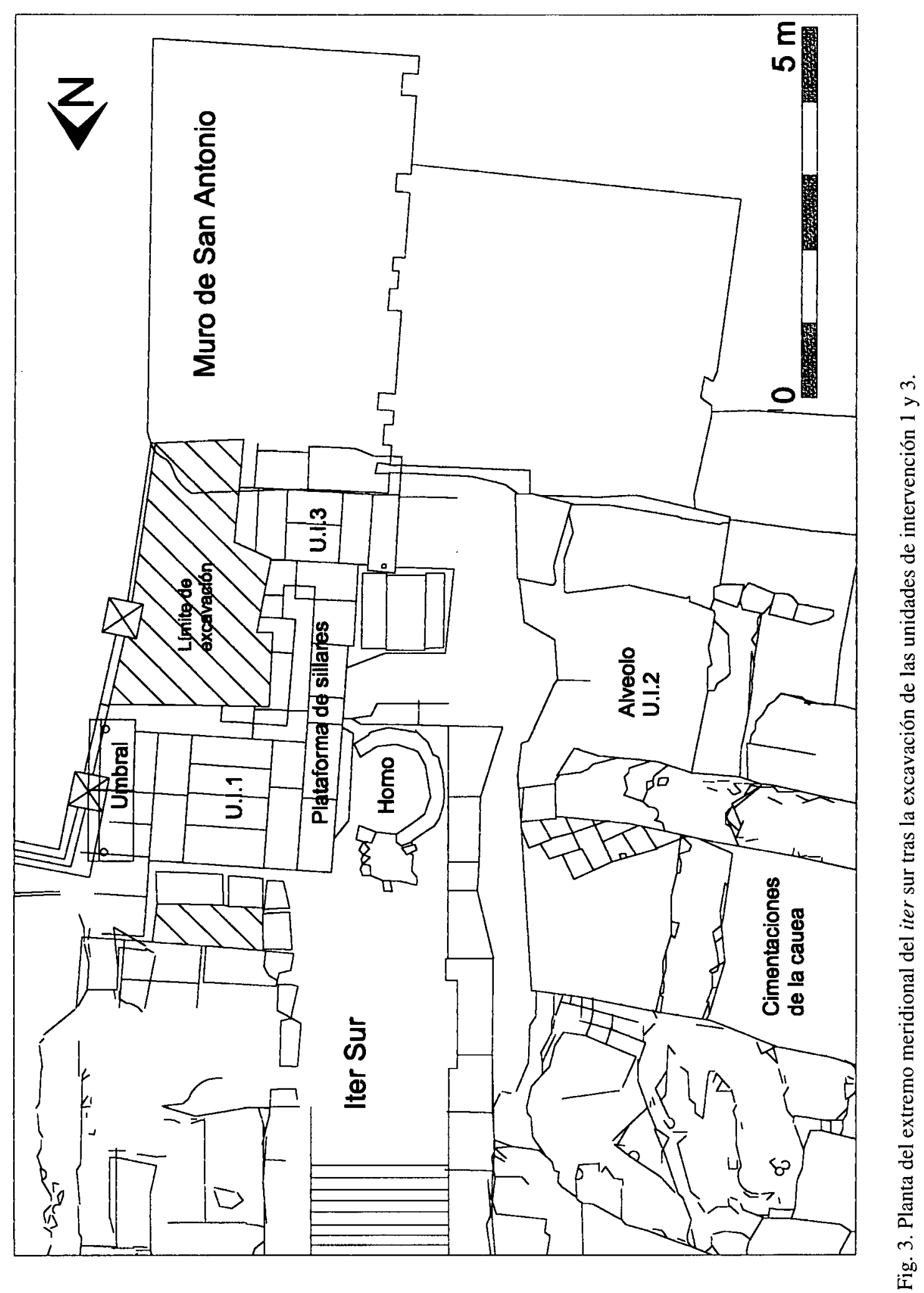



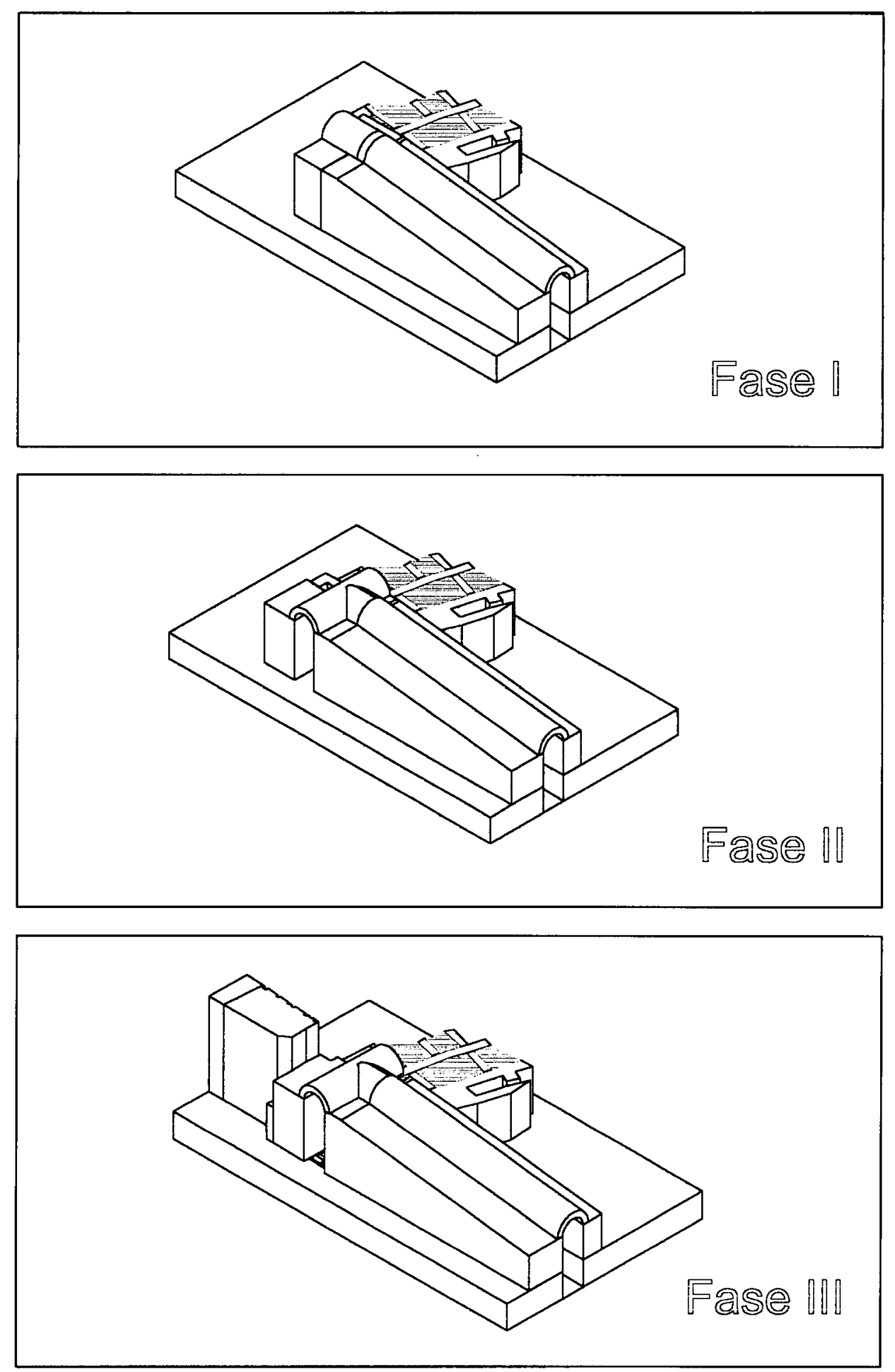

Fig. 4. Propuesta de reconstrucción de la evolución constructiva del iter sur. (Modelización de F. Rodríguez). 
Lám. I. Aspecto del extremo meridional del iter sur antes del comienzo de la intervención.
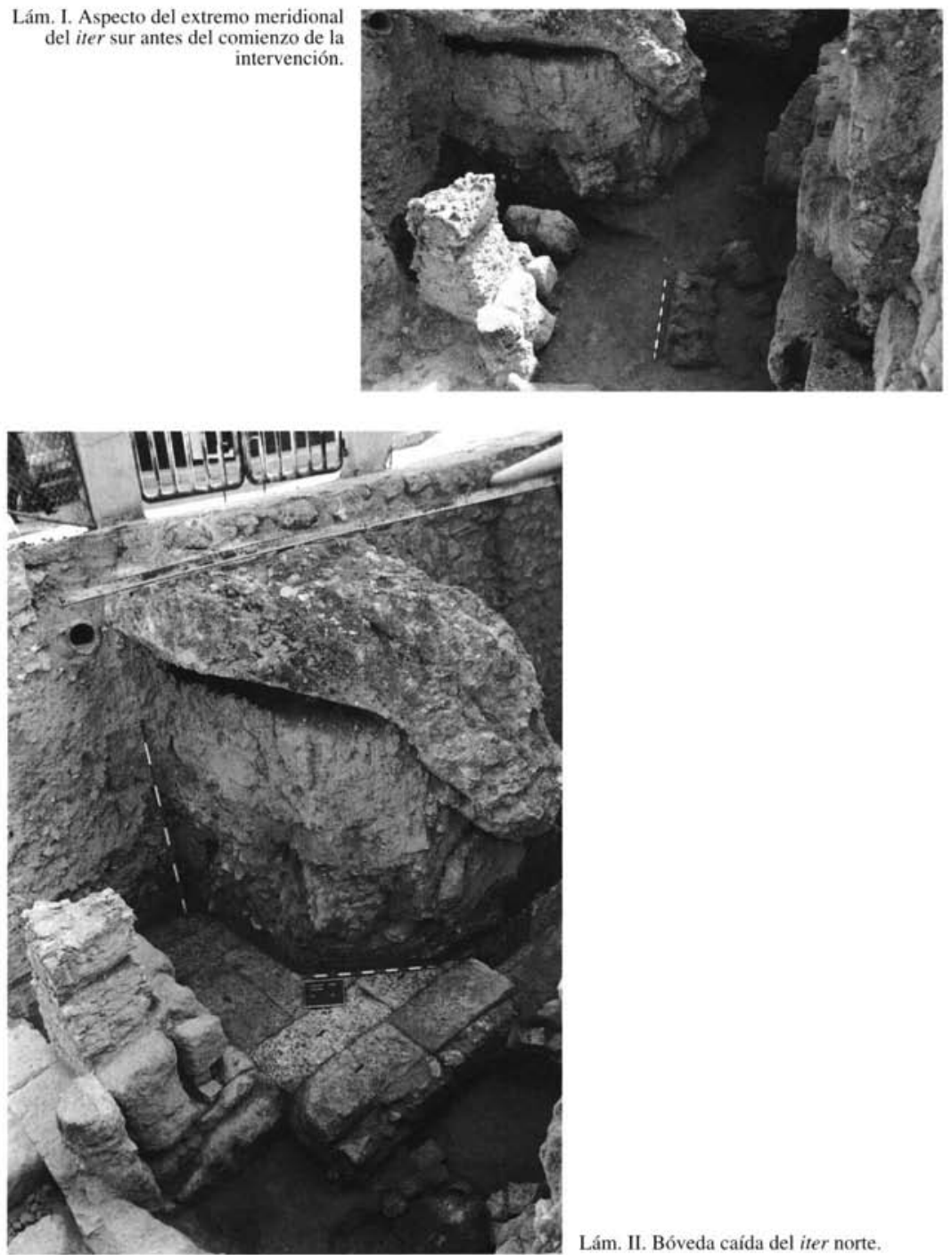

Lám. II. Bóveda caída del iter norte.

SPAL 8 (1999)

ISSN: 1133-4525 ISSN-e: 2255-3924

http://dx.doi.org/10.12795/spal.1999.i8.10 


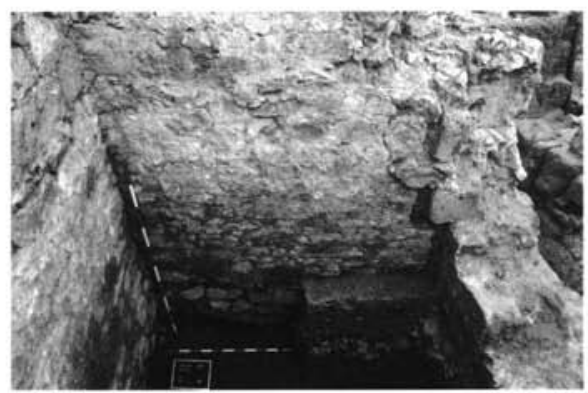

Lám. III. Alvéolo de la summa cauea (U.I. 2).

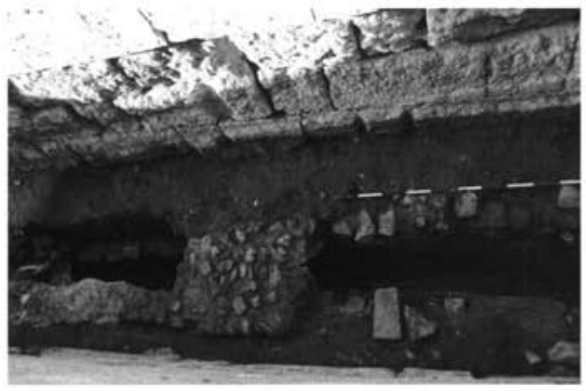

Lám. IV. Cloaca bajo el iter norte (U.I. 5).

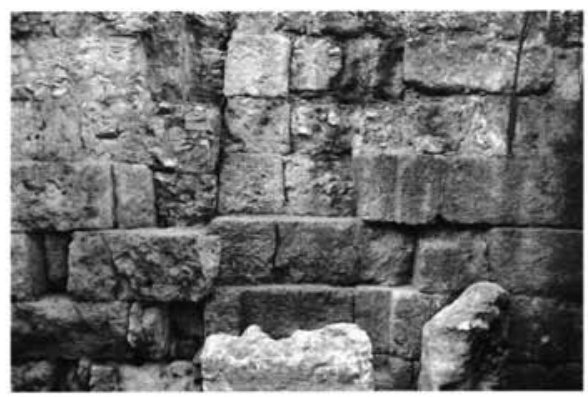

Lám. V. Detalle del muro oeste del iter sur allí donde se adosan los paramentos de sus fases I y II. 


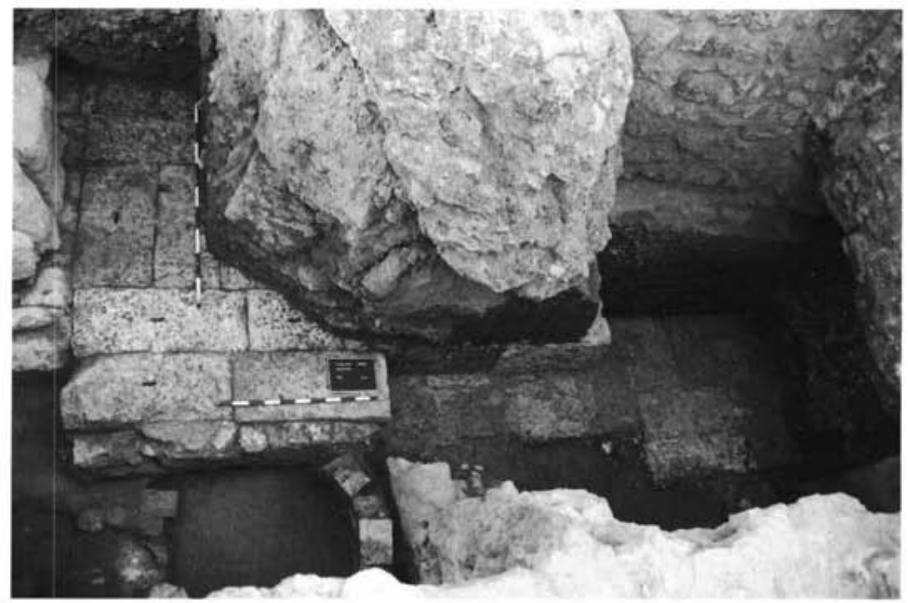

Lám. VI. Estructura de sillares en roca alberiza encargada de soportar los empujes del muro de San Antonio.

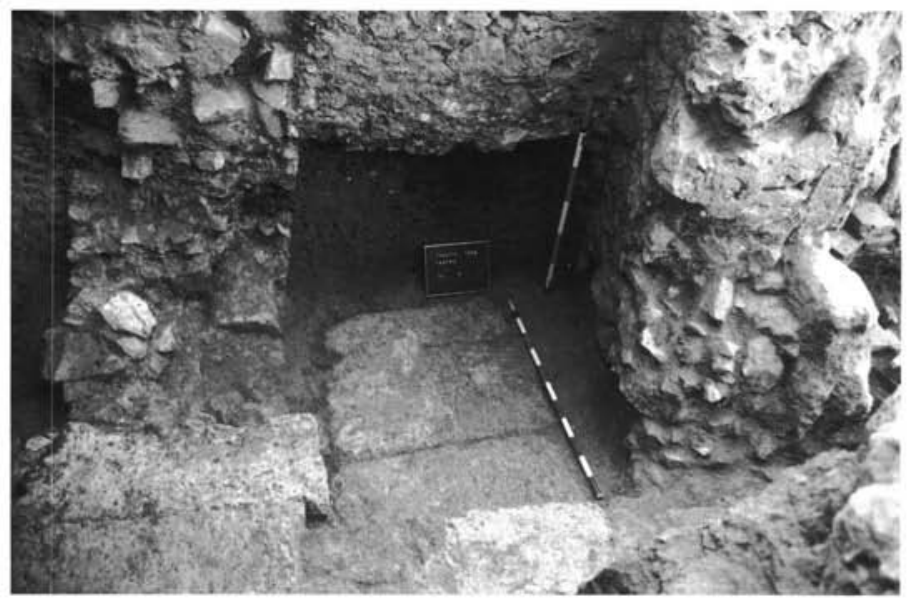

Lám VII. Detalle del relleno con sillares de uno de los alvéolos de la summa cauea en el límite meridional del iter sur. 


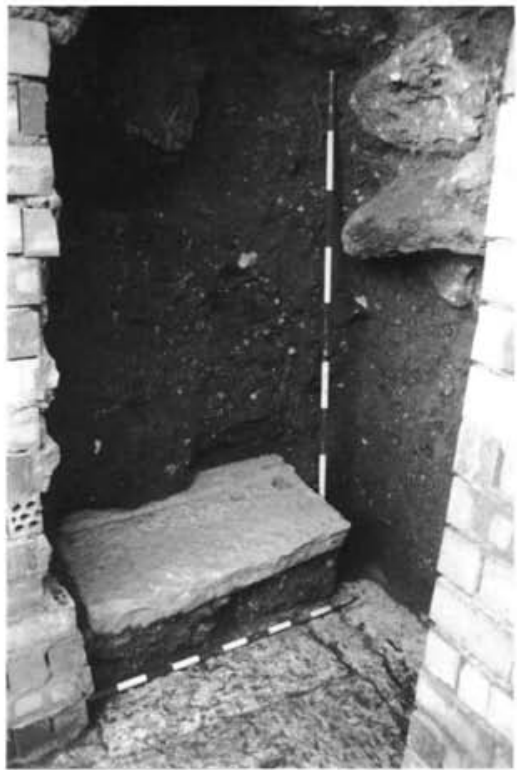

Lám. VIII. Losa del quicio de la puerta de comunicación entre el aditus maximus y el parascaenium sur.

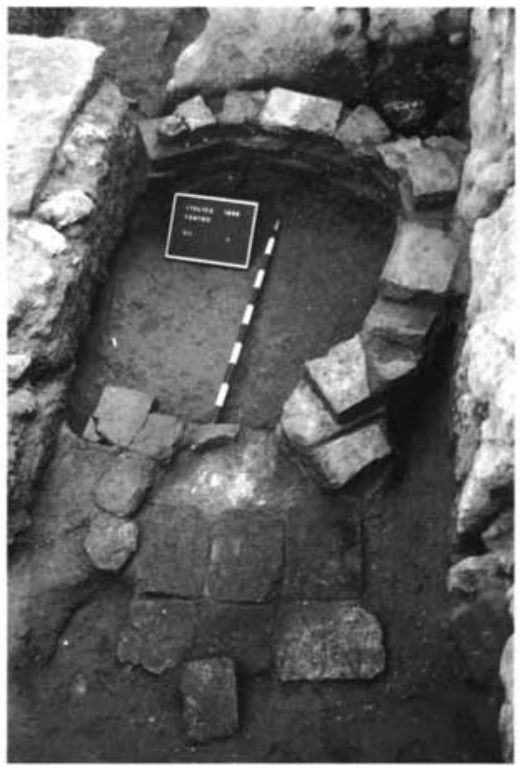

Lám. IX. Horno. 